\title{
Modulation of Conduction Block in Leech Mechanosensory Neurons
}

\author{
Adam Mar and Pierre Drapeau \\ Department of Biology, Department of Neurology and Neurosurgery, and Center for Research in Neuroscience, McGill \\ University, and The Montréal General Hospital Research Institute, Montréal, Québec, Canada H3G 1 A4
}

Conduction block is a mechanism of activity-dependent neuronal plasticity, but little is known about its possible neuromodulation. Extensive activity in leech touch $(T)$, pressure $(P)$, and nociceptive $(\mathrm{N})$ mechanosensory neurons results in conduction block of their minor receptive fields. We have examined whether the duration of conduction block could be modulated by the serotonergic Retzius neurons or by application of serotonin (5-HT). Activation of one Retzius cell reduced the duration of conduction block in $\mathrm{T}$ and $\mathrm{P}$ cell posterior fields, but their anterior fields and $\mathrm{N}$ cell fields were unaffected. Perfusion with 5-HT had stronger effects, reducing the duration of conduction block in $\mathrm{T}, \mathrm{P}$, and lateral $\mathrm{N}$ cells in the posterior fields and either reducing or more often enhancing the expression of conduction block in anterior fields. The effects of 5-HT on posterior fields

The modification of neuronal activity provides the code for behavioral change. Although the effects of previous activity, neuromodulators, and injury on synaptic efficacy are well established, less is known about how these factors might influence intrinsic electrical properties. Growing evidence suggests that changes in membrane properties along axons and dendrites can also modify impulse conduction, contributing substantially to neuronal plasticity. Early observations in vertebrate sensory afferents (Barron and Matthews, 1935; Howland et al., 1955) and at the neuromuscular junction (Krnjevic and Miledi, 1959) have demonstrated that repetitive firing can result in sporadic failure of impulses to invade some of the terminal branches. There are now numerous examples of conduction failure in various neuronal types and preparations (Tauc and Hughes, 1963; Parnas, 1972; Van Essen, 1973; Luscher et al., 1994; Spruston et al., 1995). In addition, conduction block at branch points causes variable reductions in the strength of synaptic transmission between nerve and muscle (Bittner, 1968; Atwood and Bittner, 1971), as well as between neurons (Muller and Scott, 1981; Luscher et al., 1983; Macagno et al., 1987; Wall and Bennett, 1994). Recent studies suggest that conduction block at branch points might allow selective activation of certain postsynaptic targets (Grossman et al., 1979; Gu, 1991; Wall and Bennett, 1994) or branches in the neuritic arbor (Zhang and Jackson, 1993; Spruston et al., 1995), offering intricate possibilities for plasticity.

Received Feb. 22, 1996; revised April 4, 1996; accepted April 16, 1996.

This work was supported by the Fellow of Royal Society Québec and the Medical Research Council of Canada. We thank Dr. S. Catarsi for critical reading of this manuscript.

Correspondence should be addressed to Dr. Pierre Drapeau, Department of Neurology, Montréal General Hospital, 1650 Cedar Avenue, Montréal, Québec, Canada H3G 1A4.

Copyright (C) 1996 Society for Neuroscience $0270-6474 / 96 / 164335-09 \$ 05.00 / 0$ were blocked by the nonspecific 5-HT antagonist methysergide and were partly suppressed by the $5-\mathrm{HT}_{2}$ antagonist ketanserin. To determine the site of 5-HT action, the central ganglion or peripheral skin was perfused independently. $\mathrm{T}$ and to $\mathrm{a}$ greater extent $\mathrm{P}$ cells showed a preferential sensitivity to application of 5-HT onto the central ganglion. Interestingly, medial N cells exhibited a progressive decrease in the duration of conduction block during repeated trials ("wind-up") that was unaffected by $5-\mathrm{HT}$. We conclude that secretion of $5-\mathrm{HT}$ by the Retzius cells has a central modulatory effect on the duration of conduction block in $\mathrm{T}, \mathrm{P}$, and lateral $\mathrm{N}$ cells.

Key words: conduction block; sensory neuron; serotonin; neuromodulation; receptive field; leech
Despite the considerable evidence for the occurrence of conduction block and the elaboration of its functional consequences, surprisingly few studies have examined whether and how it might be under the control of neuromodulatory influences. The best evidence comes from studies of dorsal column sensory afferents in the rat, where GABAergic (Wall, 1994a) or glycinergic (Biella and Sotgui, 1995) inputs seem to contribute to conduction failure at fine branch points and can be relieved by selective antagonists. Modulation in these cases, however, may illustrate vestigial function, uncovered only in extreme conditions such as extensive injury.

The segmented nervous system of the leech provides a useful preparation in which to investigate conduction block and its possible neuromodulation. Its touch $(\mathrm{T})$, pressure $(\mathrm{P})$, and nociceptive $(\mathrm{N})$ mechanosensory neurons have well defined major and minor receptive fields (Yau, 1976). All three cell types exhibit an afterhyperpolarization (AHP) after repetitive firing (Baylor and Nicholls, 1969) that underlies a reliable central branch point conduction failure of impulses generated from the minor fields (Yau, 1976). The leech also possesses various neuromodulators such as serotonin (5-HT), which when released from Retzius cells or applied exogenously affects multifarious behaviors (Leake, 1986). 5-HT also induces electrophysiological changes in sensory neurons, including reduction of the AHP (Belardetti et al., 1984), suggesting that 5-HT may influence impulse propagation. We tested the effects of Retzius cell activity and 5-HT on conduction block of the minor receptive fields in leech mechanosensory neurons.

\section{MATERIALS AND METHODS}

Animals and preparation. Adult leeches (Hirudo medicinalis) were obtained from Ricarimpex (Audenge, France) and maintained at room temperature in fresh spring water. The leeches were dissected in a high 
(15-20 mM) $\mathrm{Mg}^{2+}$ Ringer's solution (see below) to reduce neuronal activity. They were cut along the dorsal surface, and three to five segments were dissected from the posterior half of the animal (see Fig. 1) such that the ganglion of interest was isolated from the skin (to eliminate the major receptive field), whereas adjacent body segments were innervated via the minor receptive fields. In some preparations, all of the ganglia innervated the skin to control for a possible difference caused by injury, which was not observed. The semi-intact preparations were pinned ventral side up in a Sylgard-coated dish and viewed under a dissection microscope with transillumination. A small hole was cut through the ventral (upper) skin to expose the central ganglion so that the Retzius and mechanosensory neurons could be identified and impaled with microelectrodes under visual control.

Solutions. Most experiments were conducted in normal, leech Ringer's solution containing (in $\mathrm{mm}$ ): $115 \mathrm{NaCl} ; 4 \mathrm{KCl} ; 1.8 \mathrm{CaCl}_{2} ; 10$ glucose; and 10 Tris maleate, buffered to $\mathrm{pH} 7.4$ with $\mathrm{NaOH}$. In some experiments, Ringer's solution containing 15 or $20 \mathrm{mM} \mathrm{MgCl}_{2}$ (substituted for an equivalent concentration of $\mathrm{NaCl}$ ) was used to reduce chemical synaptic transmission (Nicholls and Purves, 1970). 5-HT or antagonists (methysergide or ketanserin) were dissolved in Ringer's solution and applied by bath superfusion between experimental trials. The stock solution of methysergide (Sandoz Canada, Dorval, Québec) was prepared in dimethylsulfoxide (DMSO) and then diluted in normal Ringer's solution, yielding a final DMSO concentration of $0.05 \%$. For these experiments, a few control recordings were performed in $0.05 \%$ DMSO, which did not seem to affect the electrophysiological properties in response to serotonin. In experiments aimed at determining the localization of the 5-HT effects on conduction block, a thin wall of Vaseline petroleum jelly (Cheeseborough-Pond's Canada, Markam, Ontario) was used to separate the central ganglion containing the mechanosensory cell bodies from the adjacent minor receptive field segment. Periodically, the vital dye Fast Green (Sigma, St. Louis, MO) was used to verify differential perfusion of each side of the Vaseline partition.

Electrophysiological recording. Intracellular recordings were made using electrodes pulled from thick-walled capillary glass $(1.0 \mathrm{~mm}$ outer diameter, $0.58-0.75 \mathrm{~mm}$ inner diameter; A-M Systems, Everett, WA) and filled with $4 \mathrm{M}$ potassium acetate (50-90 M $\Omega$ ). Voltage traces were recorded with an Axoclamp-2A amplifier (Axon Instruments, Burlingame, CA), viewed on an oscilloscope, and stored permanently as digitized signals on video cassette using a pulse code modulator (Neurodata Instrument, New York, NY).

Cells were identified by their characteristic sizes, positions, and action potential waveforms. To stimulate discrete regions on the skin innervated by $\mathrm{T}$ cells, a glass stylus was mounted on a small microphone speaker and displaced by $1 \mathrm{msec}$ gating pulses. $\mathrm{P}$ cell receptive fields were stimulated with either a glass probe for longer durations or by $1 \mathrm{msec}$ electrical shocks of 0.4-1.6 V from an isolated stimulator (World Precision Instruments, Sarasota, FL) applied via Teflon-insulated platinum wires with exposed tips placed under the skin surface. $\mathrm{N}$ cells were stimulated only by electrical shocks.

Trains of action potentials were evoked in the Retzius and sensory neurons by passing current with the recording electrode through a bridge circuit. For each trial, AHPs were generated to induce conduction block of the stimulated minor receptive field. The AHP stimulation protocol consisted of $40 \mathrm{msec}$ pulses at $10 \mathrm{~Hz}$ for a fixed period in the range of 5-20 sec to achieve a measurable duration of conduction block. Some sample spike counts were taken during these conditioning trains, and we did not see a great deal of variability within any given treatment condition.

For each cell type, the magnitude of the AHP, the input resistance (measured by current injection), the membrane potential, and the duration of conduction block were determined in each trial, every $5 \mathrm{~min}$ throughout the experiment (i.e., before, during, and after either Retzius cell activation or 5-HT application). The duration of conduction block could be measured most simply as the period during which the cells failed to respond to skin stimuli before complete recovery of their sensitivity. The cells, however, did not always fire in response to each stimulus, even in the absence of conduction block at the beginning of the experiment. Therefore, we estimated the duration of conduction block as the time required for the level of activity after the AHP to recover as much as $70 \%$ of the initial level of activity (i.e., before AHP induction). The level of activity was measured as the number of action potentials elicited by skin stimuli during a $10 \mathrm{sec}$ bin. For the analysis, the $10 \mathrm{sec}$ bin was shifted by $2 \mathrm{sec}$ intervals to obtain a more resolved measure of the duration of conduction block.

\section{ANTERIOR}

POSTERIOR

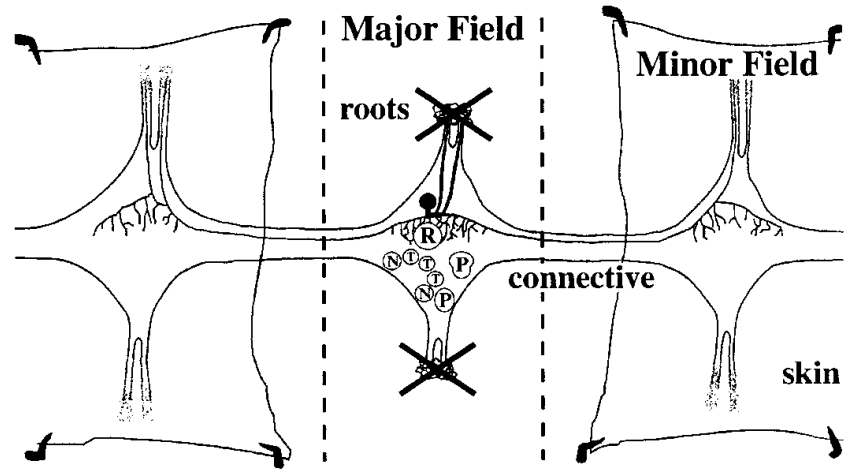

Figure 1. Schematic of a leech semi-intact preparation. Intracellular recordings were made in somata of paired touch $(T)$, pressure $(P)$, and nociceptive $(N)$ mechanosensory neurons the relative positions of which are shown in the lower half of the central ganglion. The typical branching pattern of a $\mathrm{T}$ cell is depicted in the upper half of the ganglion. In experiments testing for localization of a 5-HT effect, a Vaseline partition was set up, as indicated by the dashed lines.

The effect of each treatment was determined as a percentage change relative to the trial immediately preceding the treatment. To summarize the results obtained during many experiments for each cell type, the values for a particular treatment condition and time point (trial) were averaged; the largest change observed is reported in Results as the "maximal average reduction" (MAR) that was statistically significant $(p<0.05$ or, where indicated in the text, $p<0.01)$. An ANOVA test was used to estimate the overall significance for a particular experiment (e.g., all the data in Fig. 3B). Mean and Tukey post-hoc comparisons were then used to estimate differences at each time point (e.g., the two sets of results obtained at each 5 min interval in Fig. $3 B$ ).

\section{RESULTS}

\section{Conduction block in mechanosensory neurons}

In each of the 21 segmental ganglia of the leech there are three pairs of cells that respond to light touch (T cells), two pairs that respond to a stronger stimulus ( $\mathrm{P}$ cells), and two pairs that respond to noxious ( $\mathrm{N}$ cells) stimulation of their receptive fields (Nicholls and Baylor, 1968). Each of these mechanosensory cells sends large axons directly through the nerve roots to innervate the skin of its own segment, forming the major receptive field (Fig. 1). They also send thinner axons along the connective nerves and out the roots of adjacent ganglia to innervate contiguous regions of skin anteriorly and posteriorly, forming the minor receptive fields (Yau, 1976).

In our experiments, the skin was stimulated in one of the segments adjacent to the ganglion from which sensory neurons were impaled. To be certain that the minor and not the major field was stimulated, the nerve roots of the central segment were severed (Fig. 1). Severing the roots also greatly reduced the consequences of muscle contractions when skin stimulation occurred, and it was necessary so that stable recordings were obtained over the long duration (at least $1 \mathrm{hr}$ ) of these experiments.

Repetitive firing in the mechanosensory neurons resulted in an AHP and conduction block of the minor receptive fields that lasted many seconds. The results of the experiment shown in Figure $2 A$ illustrate this phenomenon. Each repetitive touch of the skin (at $2 \mathrm{sec}$ intervals) elicited an action potential recorded in the cell body (beginning of the trace). After a $5 \mathrm{sec}$ period of depolarizing current pulses ( $40 \mathrm{msec}$ pulse duration; $10 \mathrm{~Hz}$; eliciting 200-300 action potentials), an AHP resulted in suppression of the full action potentials recorded in the cell body for a period 
A

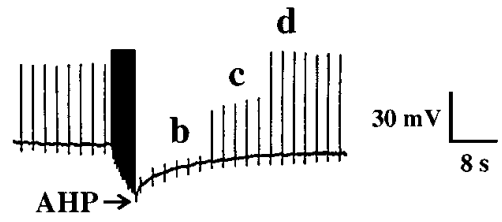

B

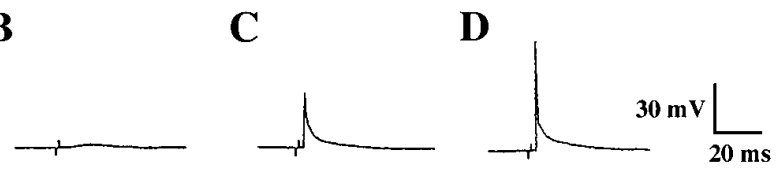

Figure 2. An AHP after repetitive firing results in a period of conduction block in a sensory neuron. $A,(\mathrm{RMP}=-42 \mathrm{mV})$ Response of a $\mathrm{T}$ cell to cutaneous stimuli delivered to its posterior field at $2 \mathrm{sec}$ intervals before and after an $A H P$ (arrow) generated by a $10 \mathrm{~Hz}, 5 \mathrm{sec}$ train of $40 \mathrm{msec}$ depolarizing current pulses. Before the AHP, each stimulus generated a full action potential recorded in the cell body. After the AHP, it took 24 sec before full spikes were observed again $(A-d)$. $B$, Immediately after the AHP $(A-b)$, there was sometimes a short period during which little or no electrotonic potential was recorded in the cell body. The small, bipolar voltage event represents the stimulus artifact and can be seen easily only on this scale. $C$, During the $24 \mathrm{sec}$ period without full spikes, blocked spikes were observed $(A-c)$ during skin stimulation that were smaller than the full action potentials. $D$, Full action potentials $(A-d)$ eventually returned. The full spikes shown here and in other figures are attenuated because of the the limited frequency response of the recorder. Action potential amplitudes of the cells throughout this study ranged between 70 and $115 \mathrm{mV}$.

of $24 \mathrm{sec}$. The duration of conduction block (see Materials and Methods) was estimated to be $22 \mathrm{sec}$.

Spikes traveled passively to the cell body during this period of conduction block and seemed smaller (Fig. 2A-c, $C$ ) before recovery of the full action potentials was observed later (Fig. 2A-d, $D)$. There are several reasons to believe that these smaller spikes are blocked action potentials and not, for example, synaptic potentials (Yau, 1975). The blocked spikes had (1) a steep rising phase and a fast decay phase, (2) a large and constant amplitude (up to $30 \mathrm{mV}$ ) that was unaffected by a high external $\mathrm{Mg}^{2+}$ concentration (which is known to block chemical synapses in the leech CNS; Nicholls and Purves, 1970), and (3) time delays after skin stimulation corresponding exactly to those of full action potentials. This conduction block is attributable to a combination of the AHP and the sensitive neural geometry, where the thin axon from the minor field meets the thicker axon near the soma (Yau, 1976).

The appearance of blocked spikes was sometimes preceded by a period during which little or no electrotonic potential was observed (Fig. $2 A-b, B$ ). The lack of spikes during this period may be attributable to a block occurring further away from the cell body.

\section{Retzius cell activity reduces conduction block in $\mathrm{T}$ and $P$ neurons}

Paired serotonergic Retzius cells are present in each segmental ganglion and contain about half of the 5-HT present in the CNS (McAdoo and Coggeshall, 1976). They are known to be modulatory neurons having numerous effects in the CNS and periphery (Leake, 1986; Carretta, 1988). Retzius cells project to the periphery over several segments and innervate every tissue examined (Leake, 1986). They release 5-HT into the skin as well as into the bloodstream (Willard, 1981), modulate feeding (Lent and Dickinson, 1984) and swimming behaviors (Kristan and Nusbaum, 1982), and suppress the AHP of the T cell (Belardetti et al., 1984;
A

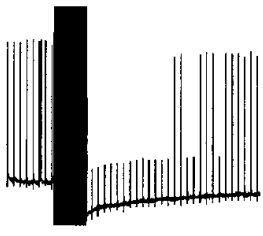

Control

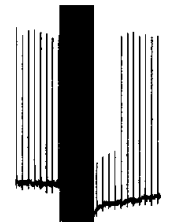

After Retzius (10 min)

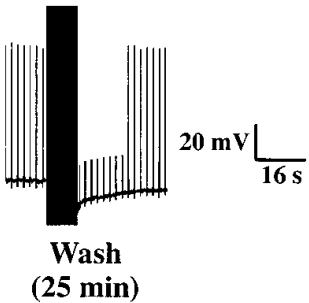

$\mathbf{T}$ cell
B

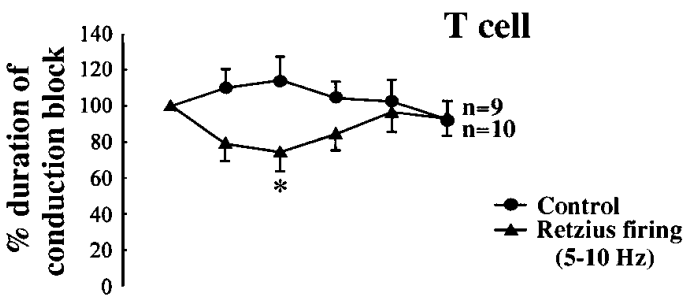

C

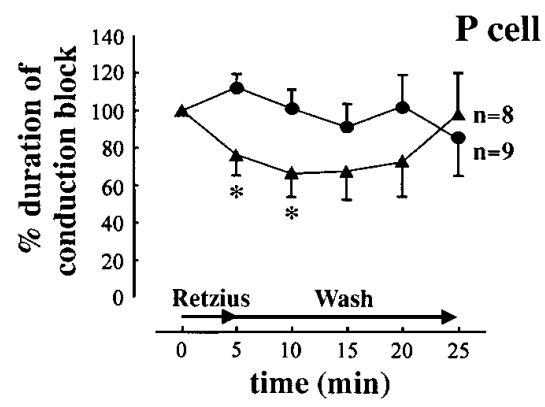

Figure 3. Retzius cell activity reduces the duration of conduction block in $\mathrm{T}$ and $\mathrm{P}$ cells. $A$, Example of a decrease in the duration of conduction block from the posterior field of a $\mathrm{T}$ cell $10 \mathrm{~min}$ after firing action potentials in the Retzius cell at $5-10 \mathrm{~Hz}$ for $5 \mathrm{~min}$ [compare left (RMP $=$ $-49 \mathrm{mV})$ and middle $(\mathrm{RMP}=-51 \mathrm{mV})]$. Fifteen minutes later, the duration of conduction block returned toward control levels [right $(\mathrm{RMP}=-48 \mathrm{mV})] . B, C$, Summary of the time course of conduction block for $\mathrm{T}$ cells and $\mathrm{P}$ cells after the Retzius cells were activated (triangles) compared with when they were held silent (circles). The means are plotted relative to the initial values, and the error bars in this and all other figures represent the SE. Asterisks indicate significant differences from control values for all figures $\left({ }^{*} p<0.05\right.$; $\left.{ }^{*} p<0.01\right)$.

Catarsi and Brunelli, 1991). To test for a modulatory effect of Retzius cells on the mechanosensory neurons, we elicited action potentials in one of the Retzius cells and then measured the duration of conduction block for sensory neuron responses to skin stimulation.

After a steady basal duration of conduction block was obtained in the posterior field of the sensory neurons, the Retzius cell was stimulated (by intracellular current injection) to fire action potentials for $5 \mathrm{~min}$ at $5-10 \mathrm{~Hz}$, similar to the level of activity seen in vivo (Leake, 1986). As shown in Figure $3 A$, the initial duration of conduction block for a $\mathrm{T}$ cell during posterior field stimulation (left) was reduced $10 \mathrm{~min}$ after firing action potentials in the Retzius cell (middle). While the preparation was washed continually with Ringer's solution, the duration of conduction block increased to approach control levels 15 min later (right). The results are summarized in Figure $3 B$ for T cells and $3 C$ for $\mathrm{P}$ cells. After the stimulation of the Retzius cell was stopped, the duration of conduction block was reduced slightly during the first few trials (15-20 min) for averaged data from both cell types. It did not return fully to control levels until $\sim 15$ min later. Significant 
A

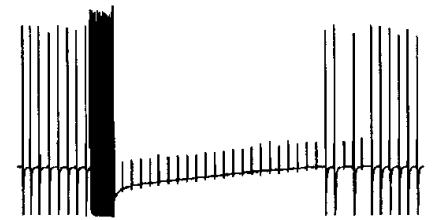

First trial (0 min)

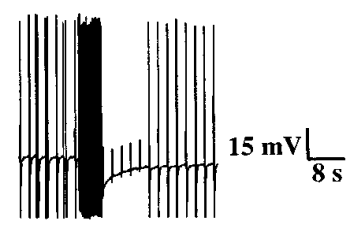

Third trial (10 min)
B

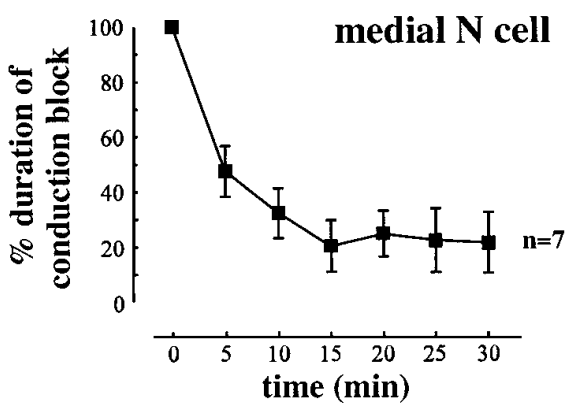

Figure 4. Progressive reduction of conduction block duration of the medial $\mathrm{N}$ neuron during repeated trials. $A$, The first trial shows a prolonged duration of conduction block after induction of an AHP [left $(\mathrm{RMP}=-48 \mathrm{mV})]$. Ten minutes later, a third trial resulted in a considerably briefer duration of conduction block [right $(\mathrm{RMP}=-46 \mathrm{mV})]$. $B$, Summary of data for several medial $\mathrm{N}$ cells shows that a reduction in the duration of conduction block was induced after the first few trials (10-15 $\mathrm{min})$ and was maintained for at least $30 \mathrm{~min}$.

reductions were observed at $10 \mathrm{~min}$ in T cells (MAR, $23 \pm 12 \%$; $n=10$; see Materials and Methods) and at 5 and $10 \mathrm{~min}$ in $\mathrm{P}$ cells (MAR, $24 \pm 9 \%$ and $34 \pm 11 \% ; n=8$ ). The response was quite variable, however, in that 5 of $10 \mathrm{~T}$ cells and 4 of $8 \mathrm{P}$ cells showed reductions of $<25 \%$, whereas 3 of $10 \mathrm{~T}$ cells and 3 of $8 \mathrm{P}$ cells showed reductions of $>50 \%$. Retzius cell activity was not observed to alter significantly the AHP amplitude, input resistance, or membrane potential of any cell types.

In contrast to the reduction of the duration of conduction block after posterior field stimulation, Retzius cell activity had no apparent effect on conduction block of the anterior fields; likewise, the lateral $\mathrm{N}$ cells were unaffected by Retzius cell activity (not shown). We were unable to test for modulation in the medial $\mathrm{N}$ cell because in trying to establish a basal duration of conduction block, we observed a progressive reduction in the duration of conduction block during repeated trials. This is illustrated in Figure $4 A$, where during the first trial (left) there was a prolonged duration of conduction block after induction of the AHP. A second trial was performed 5 min later, and then 10 min later a third trial (right) resulted in a far briefer duration of conduction block. As summarized in Figure $4 B$, the reduction in the duration of conduction block (which was completely eliminated in four of the seven cells examined) was induced after the first few trials and was maintained as long as the recordings were stable. Concurrent with these reductions in the duration of conduction block was a drop in the amplitude of the AHP $(24 \pm 8 \%)$, the input resistance $(19 \pm 9 \%)$, and a slight depolarization of the resting potential $(\sim 2$ $\mathrm{mV}$ ). Retzius cell activation (or 5-HT application; see below for effects on other cells) or suppression of activity (bypassing hyperpolarizing current) did not seem to influence this already marked reduction in the duration of conduction block (not shown).

Because the Retzius cells are serotonergic, we examined the
A

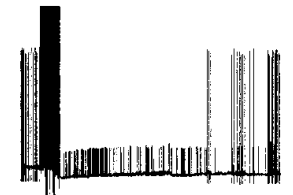

Control

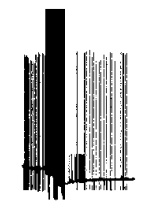

After 5-HT (15 min)

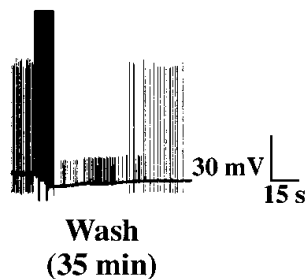

T cell
B

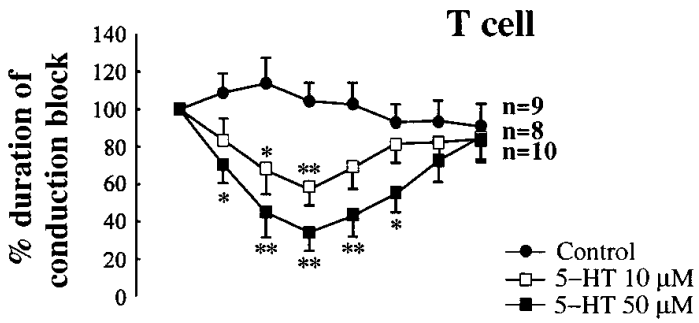

C

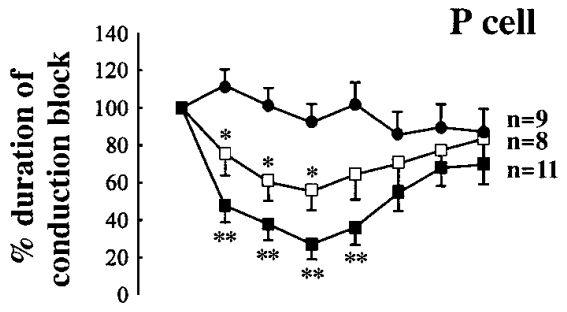

D

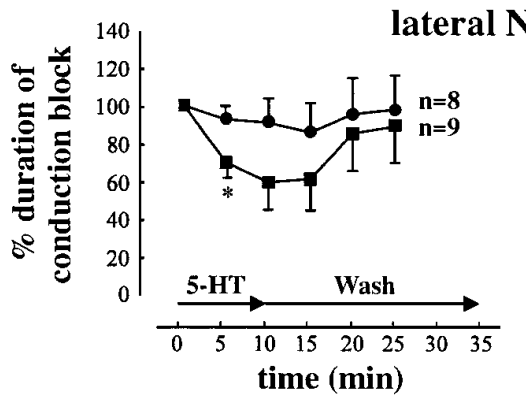

Figure 5. Exogenous 5-HT reduces the duration of conduction block in the posterior fields of mechanosensory neurons. This experiment is similar to that of Figure 3 except that 5-HT was applied (instead of firing the Retzius cells). $A$, Reduction in the duration of conduction block 15 min after $50 \mu \mathrm{M} 5$-HT application [compare left $(\mathrm{RMP}=-52 \mathrm{mV})$ and middle $(\mathrm{RMP}=-50 \mathrm{mV})]$ followed by recovery [right $(\mathrm{RMP}=-50 \mathrm{mV})]$. Summary of the results for $\mathrm{T}$ cells $(B), \mathrm{P}$ cells $(C)$, and lateral $\mathrm{N}$ cells $(D)$.

effects of bath application of 5-HT on either posterior or anterior field properties to determine whether 5-HT secretion by the Retzius cells directly modulates the sensory neurons.

\section{5-HT reduces conduction block of the posterior fields}

To test whether 5-HT has any modulatory effect on sensory neuron minor fields, different concentrations of 5-HT $(1,10$, or 50 $\mu \mathrm{M})$ were perfused onto the preparation after a steady, basal duration of conduction block was achieved in $\mathrm{T}, \mathrm{P}$, and lateral $\mathrm{N}$ cells. As described above, a steady baseline could not be obtained in the medial $\mathrm{N}$ cells because of progressive reduction in the duration of conduction block. Figure $5 A$ (left) shows a recording from a $\mathrm{P}$ cell stimulated in its posterior field and shows a long duration of conduction block after induction of an AHP.

After $50 \mu \mathrm{M} 5$-HT was applied for $10 \mathrm{~min}$, the preparation was 
washed continually with normal Ringer's solution, and another trial was performed on the P cell 5 min later. At this time (15 min into the experiment), there was a marked decrease in the duration of conduction block (Fig. $5 \mathrm{~A}$, middle). This was not attributable to a decrease in the number of action potentials during induction of the AHP, because if anything, 5-HT was sometimes observed to increase the number of action potentials slightly. As we have observed and other authors have reported (Van Essen, 1973; Yau, 1976), when there was a greater number of action potentials in the conditioning train, there was an increase in the subsequent AHP and duration of conduction block, which is actually the opposite of what we observed after 5-HT application. So, although changes in excitability may underlie the changes in duration of conduction block, this was probably not because of changes in excitability during the conditioning train.

After $25 \mathrm{~min}$ of washing (35 min into the experiment), the duration of conduction block increased and approached control values (Fig. 5A, right). The results for $\mathrm{T}$ and $\mathrm{P}$ cells are summarized in Figure $5 B$ and $C$, respectively. There was a large reduction $(p<0.01)$ in the average duration of conduction block in the posterior field during application of $50 \mu \mathrm{M}$ 5-HT (MAR, $67 \pm 9 \%$ in T cells, $n=10 ; 73 \pm 8 \%$ in P cells, $n=11$ ), with 7 of the $10 \mathrm{~T}$ cells and 10 of the $11 \mathrm{P}$ cells showing reductions of $>25 \%$ in the presence of $50 \mu \mathrm{M} 5-\mathrm{HT}$.

T cells showed a decreased AHP (MAR, $26 \pm 8 \% ; n=10)$ and decreased input resistance (MAR, $14 \pm 4 \% ; n=10)$ in the presence of $50 \mu \mathrm{M} 5$-HT. No significant change in membrane potential was observed, although there was often a slight hyperpolarization $(\sim 2 \mathrm{mV})$, as described previously by Belardetti et al. (1984). P cells showed a decreased AHP (MAR, $27 \pm 6 \% ; n=$ $11)$, a slight $(6 \pm 4 \%)$ but insignificant lowering in input resistance, and a hyperpolarization of the membrane potential $(4 \mathrm{mV}$, i.e., from $-48 \mathrm{mV}$ to $-52 \mathrm{mV} ; p<0.05)$. The $\mathrm{T}$ and $\mathrm{P}$ cells were also modulated, but to a lesser extent, by $10 \mu \mathrm{M} 5$-HT (Fig. 5B,C), and not detectably by $1 \mu \mathrm{M}$ 5-HT (not shown).

As can be seen in Figure $5 D$, lateral $\mathrm{N}$ cells showed a substantial decrease in the duration of conduction block for their posterior fields only at the highest $(50 \mu \mathrm{M}) 5$-HT concentration tested (MAR, $30 \pm 8 \% ; n=9$ ). This effect reversed more rapidly than for the $\mathrm{T}$ and $\mathrm{P}$ cells, requiring on average only $10 \mathrm{~min}$ (rather than $30 \mathrm{~min}$ ). Serotonin did not significantly affect the AHP amplitude, input resistance, or resting potential of the lateral $\mathrm{N}$ cells.

\section{The AHP and conduction block in posterior fields}

Previous studies have suggested that conduction block is caused by the AHP (Van Essen, 1973; Yau, 1976), which is generated by the electrogenic sodium pump and a calcium-activated potassium conductance in these neurons (Jansen and Nicholls, 1973). Furthermore, 5-HT has been demonstrated to inhibit the pump and suppress the AHP in T cells (Catarsi and Brunelli, 1991). Accordingly, serotonergic modulation of conduction block is expected to be caused by a reduction of the AHP. Although the results described above seem to be in agreement with those of previous reports, we have observed several discrepancies.

Although the duration of conduction block is predicted to be closely related to the duration and magnitude of the AHP, we found no significant correlation with these parameters. The duration of the AHP did not seem to determine conduction block, because there were many preparations in which the AHP amplitude was small and the conduction block far outlasted the duration of the AHP, or in which the AHP amplitude was large but
A

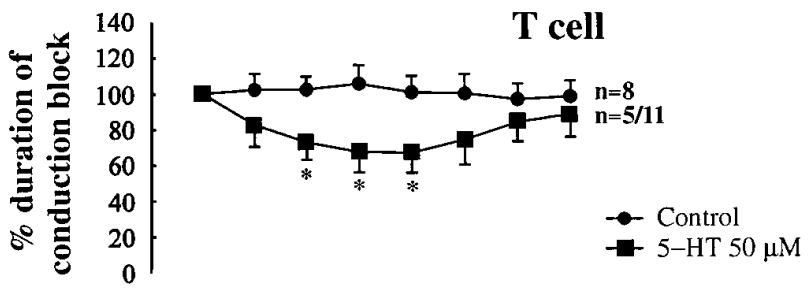

B

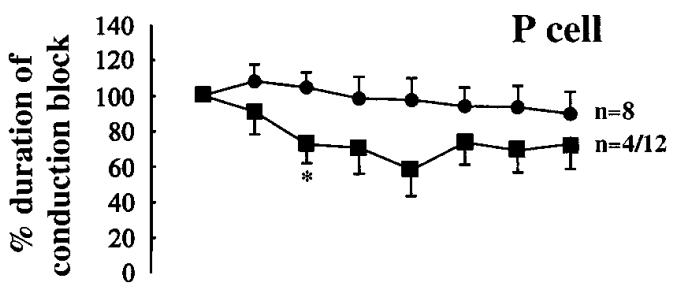

$\mathbf{C}$

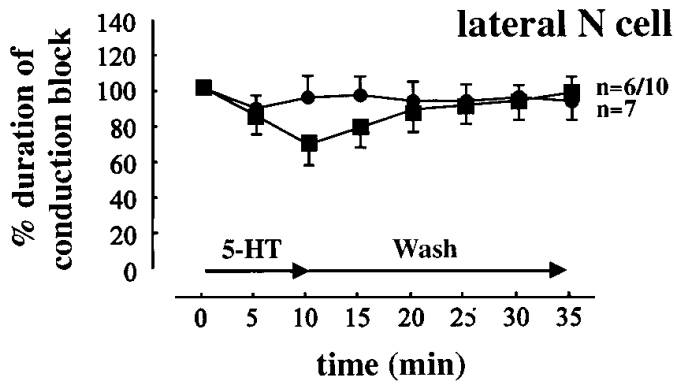

Figure 6. 5-HT reduces the duration of conduction block in some of the sensory cell anterior fields. Summary of the results for T cells $(A), \mathrm{P}$ cells $(B)$, and lateral $\mathrm{N}$ cells $(C)$ during 5-HT application (as in Fig. 5) and stimulation of the anterior field.

there was no conduction block. Thus, the AHP does not seem to be either necessary or sufficient for conduction block. Likewise, there was no significant correlation $(r<0.3)$ between the AHP and the duration of conduction block in T or P cells; furthermore, there was no correlation between the duration of conduction block and the input resistance or membrane potential

\section{5-HT either reduces or enhances conduction block of the anterior fields}

As described above for the posterior fields, some of the anterior fields also showed a reduction in the duration of conduction block during 5-HT application, but only 3 of 11 T cells, 2 of $12 \mathrm{P}$ cells, and 2 of 10 lateral $\mathrm{N}$ cells exhibited MARs of $>25 \%$. Of the remainder, a few displayed smaller reductions, whereas most showed enhancements of conduction block (see below). The data for all cells that did not show enhancements are summarized in Figure $6 A$ for T cells, $6 B$ for $\mathrm{P}$ cells, and $6 C$ for lateral $\mathrm{N}$ cells. Although the reductions were somewhat smaller (MAR, $33 \pm 9 \%$ in T cells, $n=5$; MAR, $28 \pm 11 \%$ in P cells, $n=4)$, they had time courses similar to 5-HT-induced reductions in the posterior field.

Interestingly, in the anterior fields a large proportion of $\mathrm{T}, \mathrm{P}$, and lateral $\mathrm{N}$ cells showed an increased duration of conduction block in response to 5-HT application, as illustrated in Figure 7. A typical recording is given in Figure $7 A$, where at the beginning of the trace on the left, a $\mathrm{T}$ cell responded with an action potential each time its anterior field was touched. After induction of an AHP, the T cell showed conduction block that recovered slowly, similar to the examples described above. Application of $50 \mu \mathrm{M}$ 
A

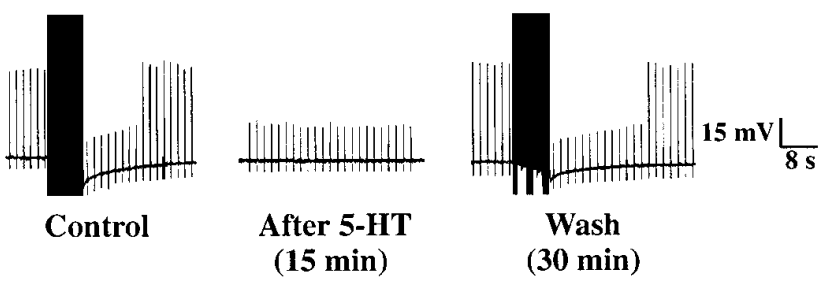

B

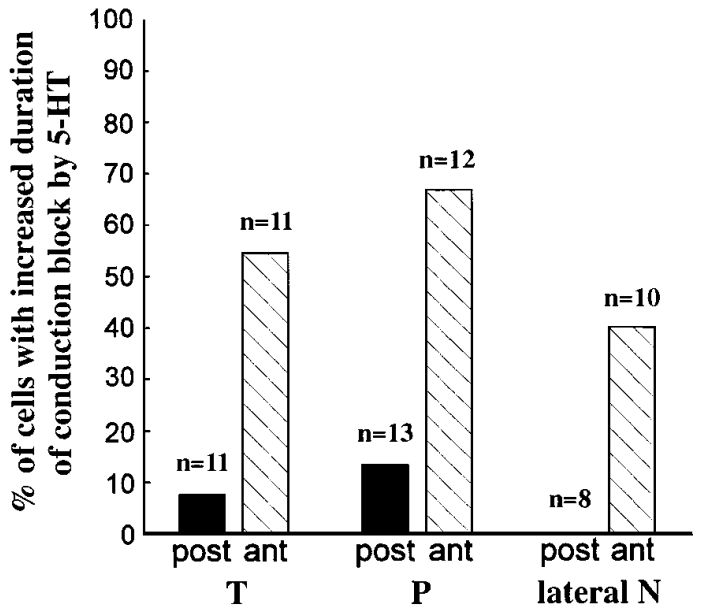

Figure 7. 5-HT enhances conduction block in about half of the sensory cell anterior fields. $A$, A typical trial in a T cell, where an AHP caused conduction block [left $(\mathrm{RMP}=-51 \mathrm{mV})]$. This $\mathrm{T}$ cell showed conduction block during skin stimulation $15 \mathrm{~min}$ after 5-HT $(50 \mu \mathrm{M})$, without requiring the induction of an AHP [middle $(\mathrm{RMP}=-53 \mathrm{mV})]$. Fifteen minutes after washing out the 5-HT, full spikes could be observed again and required the induction of an AHP to cause conduction block, with a duration similar to that of control values [right $(\mathrm{RMP}=-54 \mathrm{mV})]$. $B$, Summary of the proportion of cells showing enhancements of conduction block after 5-HT application in the anterior fields.

5-HT (for $10 \mathrm{~min}$ followed by a $5 \mathrm{~min}$ wash), however, resulted in blocked spikes without requiring induction of an AHP (middle). After an additional 15 min wash, the $\mathrm{T}$ cell again fired an action potential each time it was touched (beginning of panel on right), as under control conditions, and when an AHP was induced, conduction block was observed and its duration was similar to that of control values (end of panel on right). Figure $7 B$ (hatched bars) summarizes the results, showing the fraction of each cell type displaying an enhancement of conduction block in the anterior field ( 6 of $11 \mathrm{~T}$ cells, 8 of $12 \mathrm{P}$ cells, and 4 of 10 lateral $\mathrm{N}$ cells). Enhancements in some of the posterior fields also were observed (solid bars) in only a small fraction of the $\mathrm{T}(1$ out of 11$)$ and $\mathrm{P}$ cells ( 2 out of 13 ) but in none of the 10 lateral $\mathrm{N}$ cells. These results suggest that in some of the sensory neurons, 5-HT enhances conduction block without requiring an AHP. Interestingly, when sensory neurons displayed an enhancement of anterior field conduction block, it was usually accompanied by a small (1-4 mV) but insignificant hyperpolarization of the resting potential.

\section{The effects of 5-HT are largely central}

In the experiments described above, 5-HT was applied to the entire preparation. To distinguish between peripheral and central 5-HT effects, a Vaseline partition was used to perfuse $50 \mu \mathrm{M}$ 5-HT onto either the peripheral skin or the central ganglion differentially. Because the modulation of conduction block in $\mathrm{N}$ cells was too variable to measure accurately, we limited our measurements to $\mathrm{T}$ and $\mathrm{P}$ cells.
A

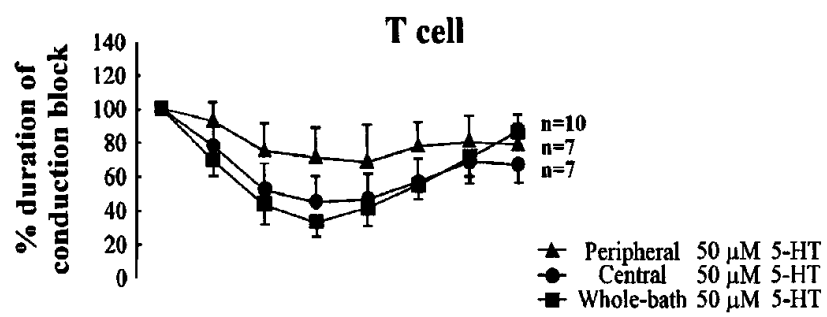

B

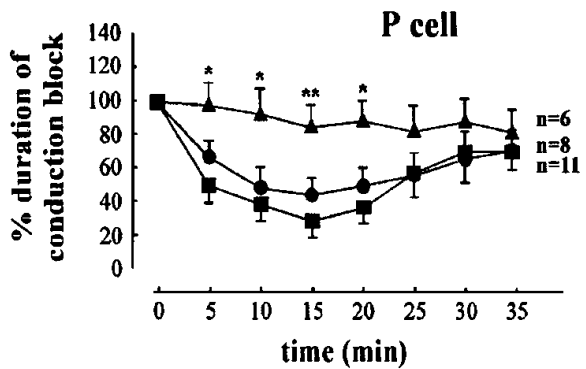

Figure 8. Perfusion of 5-HT onto the central ganglion, but not the peripheral skin, reduced conduction block similar to whole-bath 5-HT application. $A, 5-\mathrm{HT}$ applied to the peripheral skin of T cells gave a small reduction in the duration of conduction block. 5-HT applied to the central ganglion reduced conduction block, closer to that for whole-bath perfusion. $B, 5-\mathrm{HT}$ applied to the skin of $\mathrm{P}$ cells showed only a very small reduction in the duration of conduction block. 5-HT applied to the central ganglion reduced conduction block, similar to that for whole-bath perfusion.

As shown in Figure $8 A$ for $\mathrm{T}$ cell posterior fields, perfusion of the peripheral skin resulted in a smaller reduction in the duration of conduction block than that observed with whole-bath perfusion (up to $30 \pm 18 \% ; n=7$ ). Perfusion of the central ganglion resulted in a reduction (up to $55 \pm 12 \% ; n=7$ ) that approached that observed by whole-bath perfusion $(67 \pm 9 \% ; n=10)$. These results suggest that 5-HT has a weak peripheral and a stronger central effect on $\mathrm{T}$ cell posterior fields. As described previously, 6 of $11 \mathrm{~T}$ cells showed enhanced conduction block in the anterior field to whole-bath perfusion of 5-HT. When only the skin was perfused, none of the $\mathrm{T}$ cells showed enhancements, whereas perfusion of the ganglion enhanced conduction block in half (3 of 6) of the T cells (not shown), similar to the fraction responding to whole-bath perfusion. These results suggest that 5-HT has a central effect on enhancement of conduction block in anterior fields.

As shown in Figure $8 B$, peripheral perfusion of 5-HT had little effect on the duration of conduction block in the $\mathrm{P}$ cell posterior field (MAR, $16 \pm 8 \% ; n=6$ ). In contrast, perfusion of the ganglion resulted in a reduction in the duration of conduction block (up to $57 \pm 17 \% ; n=8$ ) similar to that observed with whole-bath perfusion $(73 \pm 8 \% ; n=11)$. As described above for anterior fields of P cells, whole-bath perfusion of 5-HT enhanced conduction block in 8 of $12 \mathrm{P}$ cells. Perfusion of the skin enhanced conduction block in none of the $6 \mathrm{P}$ cells examined, whereas perfusion of the ganglion resulted in enhanced conduction block in three of six P cells (not shown), similar to the observations with $\mathrm{T}$ cells and with bath perfusion of $\mathrm{P}$ cells. These results indicate that 5-HT has a predominantly central effect on both the posterior and anterior fields of $\mathrm{P}$ cells. 
A

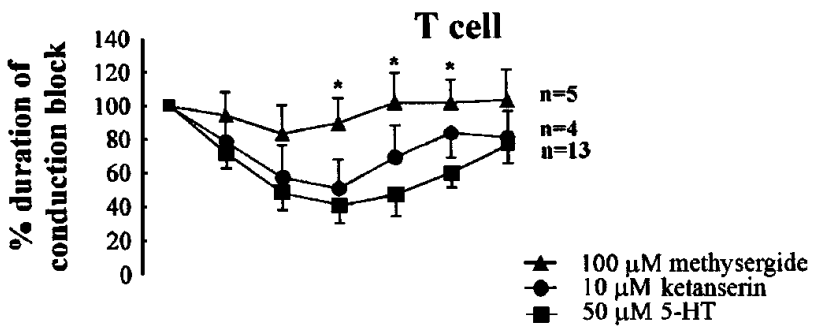

B

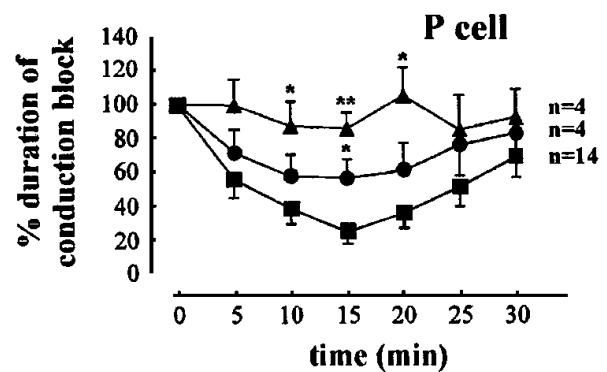

Figure 9. 5-HT antagonists suppress the reduction in the duration of conduction block induced by 5 -HT. For T cells $(A)$ and $\mathrm{P}$ cells $(B)$, the nonspecific antagonist methysergide $(100 \mu \mathrm{M})$ suppressed the reduction in the duration of conduction block from the posterior fields by 5-HT. The 5- $\mathrm{HT}_{2}$ antagonist ketanserin $(10 \mu \mathrm{M})$ also suppressed the reduction in the duration of conduction block, but to a lesser extent

\section{Pharmacology of the 5-HT modulation of posterior fields}

To examine the pharmacological profile of the 5-HT effects on sensory cells, we examined the ability of 5-HT antagonists to suppress reductions in the duration of conduction block in posterior fields. The nonspecific 5-HT antagonist methysergide (100 $\mu \mathrm{M})$, which previously has been shown to suppress 5-HT-induced reductions of the AHP in T cells (Belardetti et al., 1984), strongly $(p<0.01)$ blocked the reduction in the duration of conduction block induced by $50 \mu \mathrm{M} 5$-HT in both $\mathrm{T}$ (Fig. $9 A$; MAR, only $10 \pm 14 \% ; n=5$ ) and P cells (Fig. 9B; MAR, only $15 \pm 12 \%$; $n=4)$.

Mammalian 5-HT receptors have diverse subtypes, some of which have selective antagonists (Peroutka, 1988). In the leech, the 5- $\mathrm{HT}_{2}$-selective antagonist ketanserin blocks a 5-HT-activated cation conductance in P cells (Sanchez-Armass et al., 1991). Ketanserin $(10 \mu \mathrm{M})$ caused a partial suppression of the reduction in the duration of conduction block induced by 5 -HT in T cells (Fig. 9A) and P cells (MAR, $41 \pm 10 \% ; n=4$ ) (Fig. 9B). These results are consistent with 5-HT activation of receptors on the sensory cells, but more than one subtype of receptor is likely to be involved.

\section{DISCUSSION}

We have observed that the duration of conduction block in mechanosensory neurons was modulated by serotonergic Retzius cell activity, and more so by 5-HT application, and was sensitive to 5-HT antagonists. In particular, the posterior fields showed a reduction in the duration of conduction block, whereas the anterior fields showed mainly an enhancement. These effects of 5-HT on $\mathrm{T}, \mathrm{P}$, and lateral $\mathrm{N}$ cells were mostly central, acting near the ganglion more than in the periphery. Although the AHP was reduced by $5-\mathrm{HT}$ in $\mathrm{T}$ and $\mathrm{P}$ (but not $\mathrm{N}$ ) cells, the AHP magnitude was not obviously related to the duration of conduction block. Furthermore, the input resistance of $\mathrm{T}$ and $\mathrm{P}$ (but not $\mathrm{N}$ ) cells was reduced by 5-HT, and the resting potential of $\mathrm{T}$ and $\mathrm{P}$ cells was slightly hyperpolarized. Finally, the medial $\mathrm{N}$ cell had an unusual activity-dependent reduction in the duration of conduction block that was not reduced further by $5-\mathrm{HT}$. We discuss below the possible mechanisms and consequences of serotonergic modulation on the receptive field properties of the mechanosensory neurons.

\section{Effects of Retzius cell activity and 5-HT on conduction block}

The effects of 5-HT on the duration of conduction block were more pronounced than the effects of Retzius cell stimulation. Posterior fields were affected in a similar but lesser manner by Retzius cell activity in that the duration of conduction block was reduced in both T and P cells. Unlike 5-HT application, however, Retzius cell activity did not affect the duration of conduction block in $\mathrm{N}$ cells and was without effect in the anterior fields. The simplest explanation for these discrepancies is that the Retzius cells released less than the $10 \mu \mathrm{M} 5$-HT required to observe a consistent effect under our experimental conditions. In fact, 5-HT levels measured in the leech blood have been shown to be 100 times less than the concentrations of exogenous 5-HT we used in these experiments (Willard, 1981), although local concentrations, e.g., near sites of release from Retzius cells, might be higher. One might expect the weaker effect of Retzius cell stimulation for several other reasons. First, we stimulated one of the Retzius cells for only a few minutes, which may not have resulted in a very high level of 5-HT secretion. Second, we stimulated only a Retzius cell in the same (central) ganglion as the mechanosensory neurons. This may have resulted in a weaker effect on the minor fields than if Retzius cells in several ganglia had been activated. Third, because the ganglia were exposed directly to the bath and were no longer contained within the ventral blood sinus, 5-HT could have diffused from its site of action within the ganglion. Finally, the Retzius cells may have been partially depleted of 5-HT because of their possible activation during the dissection. For any or all of these reasons, stimulation of a single Retzius cell likely resulted in a lower 5-HT concentration than that applied by perfusion and possibly occurring in vivo.

\section{Putative mechanisms of modulation of conduction block}

$T$ and $P$ cells

The application of 5-HT caused a reduction in the duration of conduction block for the posterior fields and for a small proportion of the anterior fields tested in both $\mathrm{T}$ and $\mathrm{P}$ cells. 5-HT has been shown to reduce the amplitude of the AHP in T cells by inhibiting the sodium pump (Catarsi and Brunelli, 1991). We observed, however, that the duration and magnitude of the AHP were not necessarily related to the duration of conduction block. One possibility is that the AHP was also induced at a site that was electrically remote from the soma, even though 5-HT was most effective at reducing conduction block when it was added to the ganglion (vs the skin). Supporting this possibility is the observation by Van Essen (1973) of an AHP recorded in a (major) ganglionic root.

In addition to modulating the sodium pump, 5-HT could also modulate conductances as it does in $\mathrm{P}$ cells, where it activates both a chloride conductance and a ketanserin-sensitive cation conductance (Sanchez-Armass et al., 1991). The partial suppression of the modulation of conduction block by ketanserin suggests that the cation channels may underlie part of the serotonergic 
effect. The majority of the anterior fields tested showed a paradoxical enhancement of conduction block in the presence of 5-HT. Because the enhancement did not require induction of an AHP, 5-HT is likely acting through a mechanism other than the sodium pump. A further understanding of the mechanisms underlying reduction and enhancement in the duration of conduction block will require direct measures of the effects of 5-HT at the site of conduction block in $\mathrm{T}$ and $\mathrm{P}$ cell processes.

\section{$N$ cells}

Conduction block of the lateral but not the medial $\mathrm{N}$ cells was modulated by 5-HT. A similar difference in responsiveness (depolarization of lateral but not medial $\mathrm{N}$ cells) to 5-HT application to the cell bodies has been reported previously (Sargent, 1977), suggesting that the medial $\mathrm{N}$ cells may lack 5-HT receptors. Several other physiological and pharmacological differences between the $\mathrm{N}$ cells have also been described (Johansen, 1991).

The lateral $\mathrm{N}$ cells were far less susceptible to modulation by 5-HT than were the T and P cells, and were unaffected by Retzius cell activity with our experimental paradigm. As in the $\mathrm{T}$ and $\mathrm{P}$ cells, however, conduction block in the lateral $\mathrm{N}$ cell was usually reduced by 5 -HT in the posterior fields, whereas either a reduction or an enhancement could be observed in the anterior fields. The weak effects of 5-HT precluded analysis of the mechanism of modulation, but the slight depolarization by $5-\mathrm{HT}$ seen by us and others (Sargent, 1977) suggests that one or more conductances may contribute to the reduction in the duration of conduction block.

The medial $\mathrm{N}$ cell was unaffected by $5-\mathrm{HT}$ and in its absence showed a progressive reduction in the duration of conduction block in successive trials. This phenomenon is akin to the "windup" of sensory cells for nociceptive stimuli seen both in other invertebrates (Clatworthy and Walters, 1993) and in vertebrates (Woolf and Thompson, 1991), where repetitive stimulation produces a progressive increase in action potential discharge. This suggests that modification of the receptive field properties of the medial $\mathrm{N}$ cell is attributable to intrinsic mechanisms rather than to extrinsic modulation.

\section{Physiological implications}

Serotonin acts as a neuromodulator in the leech, being essentially a "ready" switch so that appropriate sensory cues can elicit the resulting behaviors. For example, increased firing by the Retzius cells elevates the circulating level of 5-HT in hungry (Lent and Dickinson, 1984) or swimming leeches (Willard, 1981). Also, it has been shown that 5-HT modulates the local bending and shortening reflexes (Sahley, 1995) and increases the probability that swimming is initiated (Brodfuehrer et al., 1995) by acting on interneurons and motoneurons of the underlying circuits. Our results suggest that 5-HT also modulates the earliest stages of these networks by acting directly on the sensory neurons. By reducing conduction block, 5-HT could maintain the full size of the posterior receptive fields. At the same time, enhancing conduction block of the anterior fields would favor sensory information propagating toward the head. This is because posterior fields will readily propagate impulses toward the head, whereas anterior fields will block and thereby prevent impulses propagating toward the tail. A similar bias of information propagation toward the head has been observed in the vertebrate spinal cord (Wall, 1994b). This combination of features may be advantageous for an active animal exploring and sensing its environment.

In addition to the serotonergic modulation of these more gen- eralized increases in neuronal responsiveness, specific outputs of the sensory neurons are likely to be affected as well. For example, anterior versus posterior conduction block in $\mathrm{T}$ and $\mathrm{P}$ cells results in reduced outputs to selective interneurons and motoneurons (Muller and Scott, 1981; Gu, 1991). Accordingly, these outputs would be affected by modulation of the duration of conduction block. In addition, the local bending reflex has been shown to depend on a network of interneurons that may act to broaden effectively the receptive fields of P cells within a segment (Kristan et al., 1995). Because conduction block restricts the receptive field to the (major) central segment, this results in sensory neuron responses being limited to their corresponding segment. Serotonergic modulation could thus act directly to shift the receptive fields by maintaining the posterior minor receptive fields.

Many if not all neurons are susceptible to modulation of their firing patterns. Our observations suggest a further refinement of this concept in that activity patterns in discrete branches of the same neuron may be differentially modulated. Furthermore, because conduction block has been observed in many types of neurons, its modulation could play a broad role in neuronal and network plasticity. Interestingly, retinal horizontal cells have been shown to regulate surround antagonism in primary photoreceptor cells (Mangel and Dowling, 1985; Yang et al., 1988). Our results support the notion that in addition to serving as inputs to the CNS, sensory neuronal activity can be modulated by feedback from interneurons.

\section{REFERENCES}

Atwood HL, Bittner GD (1971) Matching of excitatory and inhibitory inputs to crustacean muscle fibers. J Neurophysiol 34:157-170.

Baylor DA, Nicholls JG (1969) After-effects of nerve impulses on signalling in the central nervous system of the leech. J Physiol (Lond) 203:571-589.

Barron DH, Matthews HC (1935) Intermittent conduction in the spinal cord. J Physiol (Lond) 85:73-103.

Belardetti F, Brunelli M, Demontis G, Sonetti D (1984) Serotonin and Retzius cells depress the hyperpolarization following impulses of leech touch cells. Brain Res 300:91-102.

Biella G, Sotgui ML (1995) Evidence that inhibitory mechanisms mask inappropriate somatotopic connections in the spinal cord of normal rat. J Neurophysiol 74:495-505.

Bittner GD (1968) Differentiation of nerve terminals in the crayfish opener muscle and its functional significance. J Gen Physiol 51:731-758.

Brodfuehrer PD, Debski EA, O'Gara BA, Friesen WO (1995) Neuronal control of leech swimming. J Neurobiol 27:403-418.

Carretta M (1988) The Retzius cells in the leech: a review of their properties and synaptic connections. Comp Biochem Physiol 91A:405-413.

Catarsi S, Brunelli M (1991) Serotonin depresses the afterhyperpolarization through the inhibition of the $\mathrm{Na}^{+} / \mathrm{K}^{+}$electrogenic pump in T sensory neurones of the leech. J Exp Biol 155:261-273.

Clatworthy AL, Walters ET (1993) Rapid amplification and facilitation of mechanosensory discharge in Aplysia by noxious stimulation. J Neurophysiol 70:1181-1194.

Grossman Y, Parnas I, Spira ME (1979) Differential conduction block in branches of a bifurcating axon. J Physiol (Lond) 295:283-305.

Gu X (1991) Effect of conduction block at axon bifurcations on synaptic transmission to different postsynaptic neurones in the leech. J Physiol (Lond) 441:755-778.

Howland B, Lettvin JY, McCulloch WS, Pitts W, Wall PD (1955) Reflex inhibition by dorsal root interaction. J Neurophysiol 18:1-17.

Jansen JKS, Nicholls JG (1973) Conductance changes, an electrogenic pump and the hyperpolarization of leech neurones following impulses. J Physiol (Lond) 441:755-778.

Johansen J (1991) Ion conductances in identified leech neurons. Comp Biochem Physiol 100A:33-40.

Kristan Jr WB, Nusbaum MP (1982) The dual role of serotonin in leech swimming. J Physiol (Paris) 78:743-747.

Kristan Jr WB, Lockery SR, Lewis JE (1995) Using reflexive behaviors of the medicinal leech to study information processing. J Neurobiol 27:380-389. 
Krnjevic K, Miledi R (1959) Presynaptic failure of neuromuscular propagation in rats. J Physiol (Lond) 149:1-22.

Leake LD (1986) Leech Retzius cells and 5-hydroxytryptamine. Comp Biochem Physiol 83C:229-239.

Lent CM, Dickinson M (1984) Serotonin integrates the feeding behavior of the medicinal leech. J Comp Physiol [A] 154:457-471.

Luscher HR, Ruenzel P, Henneman E (1983) Composite EPSPs in motoneurons of different sizes before and during PTP: implications for transmission failure and its relief in Ia projections. J Neurophysiol 49:269-289.

Luscher HR, Streit J, Quadroni R, Luscher HR (1994) Action potential propagation through embryonic dorsal root ganglion cells in culture. I. Influence of the cell morphology on propagation properties. J Neurophysiol 72:622-633.

Macagno ER, Muller KJ, Pitman RM (1987) Conduction block silences parts of a chemical synapse in the leech central nervous system. J Physiol (Lond) 387:649-664.

Mangel SC, Dowling JE (1985) Responsiveness and receptive field size of carp horizontal cells are reduced by prolonged darkness and dopamine. Science 222:1107-1109.

McAdoo DJ, Coggeshall RE (1976) Gas chromatographic-mass spectrometric analysis of biogenic amines in identified neurons and tissues of Hirudo medicinalis. J Neurochem 26:163-167.

Muller KJ, Scott SA (1981) Transmission at a "direct" electrical connexion mediated by an interneurone in the leech. J Physiol (Lond) 311:565-583.

Nicholls JG, Baylor DA (1968) Specific modalities and receptive fields of sensory neurons in the CNS of the leech. J Neurophysiol 31:740-756.

Nicholls JG, Purves D (1970) Monosynaptic chemical and electrical connexions between sensory and motor cells in the central nervous system of the leech. J Physiol (Lond) 209:647-667.

Parnas I (1972) Differential block at high frequency of branches of a single axon innervating two muscles. J Neurophysiol 35:903-914.

Peroutka SJ (1988) 5-Hydroxytryptamine receptor subtypes. Annu Rev Neurosci 11:45-60.

Sahley CL (1995) What we have learned from the study of learning in the leech. J Neurobiol 27:434-445.

Sanchez-Armass S, Merz DC, Drapeau P (1991) Distinct receptors, second messengers and conductances underlying the dual responses to serotonin in an identified leech neurone. J Exp Biol 155:531-547.
Sargent PB (1977) Transmitters in the leech central nervous system: analysis of sensory and motor cells. J Neurophysiol 40:453-460.

Spruston N, Schiller Y, Stuart G, Sakmann B (1995) Activity-dependent action potential invasion and calcium influx into hippocampal CA1 dendrites. Science 268:297-300.

Tauc L, Hughes GM (1963) Modes of initiation and propagation of spikes in the branching axons of molluscan central neurons. J Gen Physiol 46:533-549.

Van Essen DC (1973) The contribution of membrane hyperpolarization to adaptation and conduction block in sensory neurones of the leech. J Physiol (Lond) 230:509-534.

Wall PD (1994a) Control of impulse conduction in long-range branches of afferents by increases and decreases of primary afferent depolarization in the rat. Eur J Neurosci 6:1136-1142.

Wall PD (1994b) Impulses in the rostral branch of primary afferents in rat dorsal columns travel faster than those in the caudal branch. Neurosci Lett 165:75-78.

Wall PD, Bennett DLH (1994) Postsynaptic effects of long-range afferents in distant segments caudal to their entry point in rat spinal cord under the influence of picrotoxin or strychnine. J Neurophysiol 72:2703-2713.

Willard AL (1981) Effects of serotonin on the generation of the motor program for swimming by the medicinal leech. J Neurosci 1:936-944.

Woolf CJ, Thompson SW (1991) The induction and maintenance of central sensitization is dependent on $N$-methyl-D-aspartic acid receptor activation: implications for the treatment of post-injury pain hypersensitivity states. Pain 44:293-299.

Yang XL, Tornqvist K, Dowling JE (1988) Modulation of cone horizontal cell activity in the teleost fish retina. II. Role of interplexiform cells and dopamine in regulating light responsiveness. J Neurosci 8:2269-2278.

Yau KW (1975) Receptive fields, geometry and conduction block of sensory cells in the leech central nervous system. PhD thesis, Harvard University.

Yau KW (1976) Receptive fields, geometry and conduction block of sensory neurones in the CNS of the leech. J Physiol (Lond) 263:513-538

Zhang S, Jackson MB (1993) GABA-activated chloride channels in secretory nerve endings. Science 259:531-534. 